\section{A new case of Prader-Willi syndrome with chromosomal aberration}

The Prader-Willi syndrome is frequently associated with cytogenetic abnormality involving chromosome $15 .{ }^{1}$ This report presents a new case of this syndrome with the karyotype $45, X X,-15,-19,+\operatorname{der}(19), t(15 ; 19)(q 12 ; q 13)$.

The child was born at 8 months' gestation to young, unrelated parents. The mother's first pregnancy resulted in spontaneous abortion after 3 months. At birth, the baby (weight $2400 \mathrm{~g}$, length $46 \mathrm{~cm}$ ) was hypotonic and had to be artificially fed. Later she gained weight rapidly but showed psychomotor retardation.

On examination at the age of 20 months the following features were noted: obesity (height $83 \mathrm{~cm}$, weight $16 \mathrm{~kg}$ ), hypotonia, mild microcephaly (head circumference $42.5 \mathrm{~cm}$ ), low forehead, prominent glabella, light blue almond-shaped eyes, low set ears without lobes, blond hair, short neck with right torticollis, triangular upper lip,
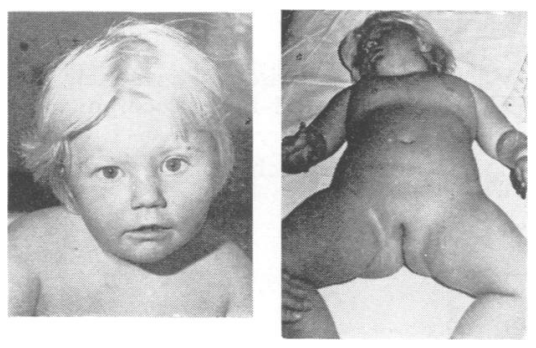

FIG 1 Proband aged 20 months.

Received for publication 27 February 1981 small hands and feet with simian creases on both hands, genu valga, underdeveloped genitalia (fig 1), normal EEG and amino acid levels, bone age 16 months, and mental age 5 months.

Chromosome analysis showed loss of a 15 and a 19 chromosome with the addition of an abnormal chromosome (fig $2 \mathrm{a}$ ) probably derived by translocation, $\mathrm{t}(15 ; 19)$ (q12;q13) followed by $3: 1$ segregation at meiosis in one of the parents, both of whose somatic chromsomes were normal (fig $2 \mathrm{~b}, \mathrm{c}$ ). The child therefore had partial monosomy for the distal long arm portion of chromosome 19, which may account for some of the unusual clinical features, such as microcephaly and simian creases, and of the short arms and proximal long arm region of chromosome 15.

Wisniewski et $a l^{1}$ and Michaelsen et $a l^{2}$ have recently discussed the relationship between the clinical and cytogenetic findings in the Prader-Willi syndrome. This case further demonstrates the heterogeneity of chromosome 15 aberrations which may be associated with this syndrome, and gives some support to the hypothesis that the presence of a lesion in $15 \mathrm{q}$ may be the underlying common factor of significance in this syndrome.

S Morić-Petrović, Ž laća, A Krstić, and $M$ ŹIVKov

Centre for Medical Genetics, Institute for Mental Health, Palmotićeva 37, Belgrade, Yugoslavia

\section{References}

1 Wisniewski L, Witt M, Ginsbera-Fellner F, Wilner J, Desnick R. Prader-Willi syndrome and a bisatellited derivate of chromosome 15. Clin Genet 1980;18:42-7.

2 Michaelsen KF, Lundsteen C. Hansen FJ. Prader-Willi syndrome and chromosomal mosaicism 46,XY/47,XY, + mar in two cases. Clin Genet 1979;16:147-50.

Requests for reprints to Dr S Morić-Petrović, Centre for Medical Genetics, Institute for Mental Health, Palmoticeva 37, Belgrade, Yugoslavia.
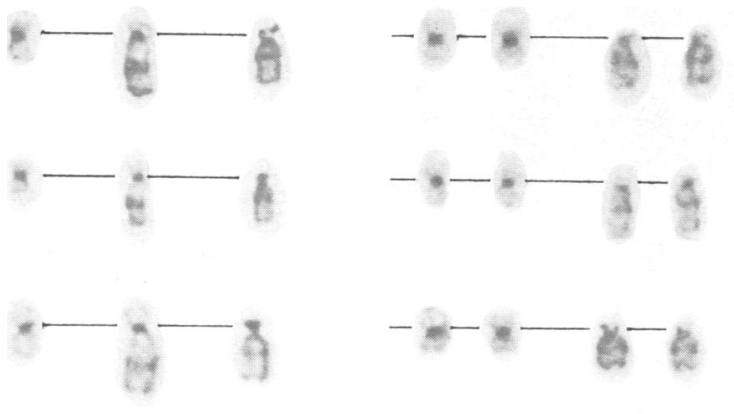

a

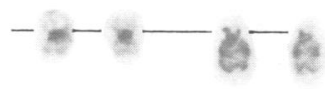

b
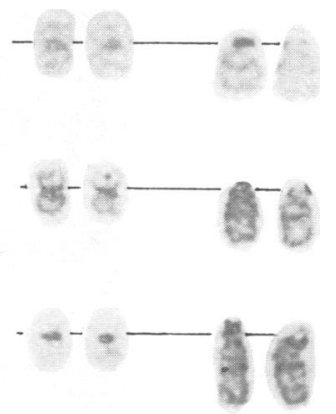

C

FIG 2 Chromosomes 15 and 19 of (a) the patient, (b) the mother, (c) the father. 